\title{
Information Communication Technology Adoption in Higher Education Sector of Botswana: a Case of Botho University
}

\author{
Clifford Matsoga Lekopanye \\ Faculty of Computing \\ Botho University \\ Gaborone, Botswana
}

\author{
Alpheus Mogwe \\ Faculty of Computing \\ Botho University \\ Gaborone, Botswana
}

\begin{abstract}
Opportunities, benefits and achievements are emerging factors for institutions, lecturers, and learners from the increasing availability of Information Communication Technologies (ICT). These factors are relevant especially for new and growing higher educational institutions (HEI) whose survival depends on, among other factors, the use of ICT to develop new organizational models to enhance their internal and external communication relationship and produce quality graduates.
\end{abstract}

Given the relevance of the topic, the researchers studied positive impact of the adoption of ICT by higher educational institutions in an attempt to justify the use of ICT. In this paper, adoption refers to institutions migrating from traditional modes of paper based school management and student engagement to a computerized environment. This shift is hoped to enhance academic development and flexibility, increase level of student engagement, enhance cost-effectiveness, and create a sustainable environment through interactive learning resources.

Although the study was conducted at a single institution (i.e. Botho University), it restricts its focus exclusively to the educational motivations for institutions to adopt ICT. In order to ascertain the current state of knowledge, an extensive review, analysis, and synthesis of the collected data and literature have been undertaken. The authors conclude the paper by identifying and examining potential benefits and achievements of institutions in adopting ICT.

\section{Keywords-ICT; Adoption; e-learning; Education}

\section{INTRODUCTION}

The acronym ICT is an umbrella acronym that includes any communication device, including but not limited to: computer, telephone, television, radio and others. There are also services and software that are associated with the aforementioned devices such as Distance Learning Software Tools and Video Conferencing Applications. According to Unwin [1], "ICT can be a catalyst by providing tools which teachers use to improve teaching and by giving learners access to electronic media that make concepts clearer and more accessible". Therefore it is evident that organizations will benefit from ICT through its adoption and be able to, as a result, reap benefits. According to Dasgupta [2], ICT adoption is "defined as the decision to accept, or invest in a technology". In light of this the use of the terms acceptance and adoption are interchangeable in this article as supported by other literatures [3].
Botswana is currently experiencing the exponential growth of the ICT sector, yet it is still lagging behind in enjoying the ICT benefits compared to other countries dominated by ICT usage [13]. This has been attributed in part to financial constraints and the uneasiness of the Botswana society to adopt ICT, due to lack and or limited knowledge on it [13]. The literature revealed that ICT adoption is not an easy task in Botswana due to countless challenges which have hampered its growth and adoption in the education sector [13], consistent with other researches [4]. Therefore, it is important that the target that Botswana has set of having an informed and educated nation [5] can be reviewed as ICT also plays a key role in achieving such. Moreover, adoption of Information Communication Technology by institutions is one of the indicators that needs to be measured during the course of Vision 2016 implementation [13].

Closely related projects to this paper exists with their emphasis and scope being different. They have focused on identifying challenges of poor ICT distribution in Botswana's Primary and or Secondary education levels, ICT training needs for teachers, challenges faced in implementing ICT in Botswana's education system, or, ICT literacy in specific target groups in Botswana [6] [13] [15] [16]. Therefore, the adoption and acceptance part has been largely ignored, hence this research is a first of its kind conducted to measure ICT adoption and acceptance for educational purposes at tertiary level in Botswana with emphasis on Botho University.

\section{RESEARCH OBJECTIVE}

To present views of Botho University staff and students towards ICT as an eliciting may lead to and/or justifies its adoption or non-adoption.

\section{LITERATURE REVIEW}

A number of conducted studies have revealed that investing in ICT is beneficial for performance and productivity [8] [9] in diverse sectors of a country's economy. Educational sector is one area which has benefited a lot from ICT and many countries that tend to do well in education have robust ICT education system [13] [14]. An ICT oriented education system provides varying benefits to both learners and educators alike, through impacting positively in improving quality, delivery and results [7] [13]. However, it is the challenges associated 
with ICT which have hampered its adoption and acceptance at various organizations [10] [13].

Many countries across the world, especially developed countries, are doing everything possible to address the ICT adoption challenges at grass root level, with others introducing initiatives of giving laptops to student and teachers to enhance their ICT skills, introduction of ICT at early levels such as Kindergarten and or providing training to teaching personnel at all levels at low costs or for free [11] [13]. In Africa, and Botswana to be precise, this is just a dream[13], since the initiatives are difficult to implement due to diverse challenges such as financial deficiency, limited ICT trained personnel and electricity distribution amongst the so many

\section{A. ICT in Botswana}

The government of Botswana adopted ICT policy in 2004, known as Maitlamo [13] and it was also revised in 2007. The goals of this policy are to; "create enabling environment, Universal service and access to information and communications facilities, to make Botswana a Regional ICT Hub". The country also have Vision 2016 which was approved in 1997, which articulates the role of ICT in an "Informed and Educated Nation" pillar [5]. However, although the government is concerned about ICT adoption, there are challenges that are encountered. According to Cummins [12], "There is also considerable difference in terms of urban and rural access to ICT services. Challenges include the relatively high cost of computers, absence of electricity in a number rural areas, and expensive Internet usage". Many Universities and colleges in Botswana have computer laboratories, but the major challenge is the computer to student ratio, many students do not have or own computers [13].

Through the ICT policy [13] [14] various areas are being addressed and Botswana is channeling her efforts to address the areas identified in the policy. One such, is the education area where efforts to integrate ICT in education is being spearheaded. There is a national e-learning committee tasked with formulating and promotion of e-learning in Botswana [14]. This initiatives are tailored to meet the shortfalls identified in the findings and recommendations contained in the Botswana ICT policy [13]. The ministry of education is trying to encourage its partners to look at e-learning as one of the possible teaching modes in Botswana with government and other stakeholders working towards achieving that vision. The ICT policy, known as Maitlamo, has noted that the government is working on broadband connection to schools, refurbishment of computers then delivered to schools and training of teachers and administrators on e-learning. Botho University is one educational stakeholder who has put forth various blended learning technologies which among includes e-learning and other interactive learning applications.

\section{RESEARCh DESIGN AND MethodOlOGY}

\section{A. Research Design}

This research was conducted at Botho University. Participants involved students, lecturers and administrative staff. The research utilized a qualitative approach and employed primary data collection through the questionnaire.
The questionnaire comprised of two sections namely the demographic details of participants and ICT Opinion questions. The questionnaire comprised of 18 questions spread into subcategories with each categories focused at obtaining data from key variables such as the level of ICT anxiety, perceived ease of use of ICT, perceived effectiveness of ICT, and perceived level of ICT acceptance. These variables are described as follow.

1) ICT Anxiety: This variable focused on finding opinions of respondents to indicate their feel and behavior in relation to ICT utilization.

2) Perceived Ease of Use of ICT: Perceived ease of use of a computer has been defined by Venkatesh (2000) as an individual's trust that using computers does not require too much effort.

3) Perceived Effectiveness of ICT: This is the opinion of respondents that indicate the level to which they are certain of the fact that ICT can be utilized to improve their job performance or daily routines.

4) ICT Acceptance: This is the opinion to measure the respondents' willingness to participate in ICT related ventures.

\section{B. Methodology}

Sampling Procedure

These questions were based in the Likert scale ranging from strongly disagree to strongly agree. This questionnaire was used to explain and calculate the perception of tertiary schools towards ICT adoption and random sampling technique was utilized.

The sample size of this research is not fairly large as the research was only based in Botho University to capture the overall ICT perspective in the Botswana Higher Education sector, thus limiting the sample size. Therefore, research of similar and better magnitude would be employed to measure such with involvement of all sample sizes and demographics.

A pilot study was done to gauge the accuracy and correctness of the questionnaire. This pilot study was done on a sample size of 10 respondents. Based on the respondents' feedback, some changes were effected to improve their accuracy and correctness. The final questionnaire was then adopted and utilized for this research.

\section{Research Instrument}

This qualitative research instrument is formulated to answer two major questions which will then be further broken down into simpler and specific sub questions. In this way, the researchers hope to generate an instrument that can easily be analyzed and interpreted. These major questions were:

\section{Main Question 1:}

What are the perceptions of the respondents versus the adoption and acceptance of ICT?

1) Sub Question

Do Botho University staff and students have any reservations or concerns about ICT adoption and acceptance? 


\section{2) Sub Question}

What are the staff and student's perceptions on the effectiveness of ICT in their school (Botho University)?

\section{3) Sub Question}

Do staff and students intend to adopt and use ICT in Botho University?

\section{Main Question 2:}

What the gaps in ICT adoption and acceptance are as identified from the questionnaire?

\section{Assumption}

The assumption tested was: a positive feeling towards the effectiveness and usefulness of ICT in tertiary schools is a sign of computer technology adoption.

\section{RESEARCH ANALYSIS AND RESULTS}

The study used qualitative data to examine ICT adoption and acceptance in tertiary institutions. These results are based on the analysis of the participants' views depending on the research variables advanced herein.

Qualitative data summaries were obtained and Microsoft Excel used to generate relevant charts for the data. Data summaries of demographic data was collected to provide percentages of describing characteristics of the population that participated in giving responses. There were two variables used for demographic data, namely; age and qualification. Fig.1 below shows the results of the age demographic variable.

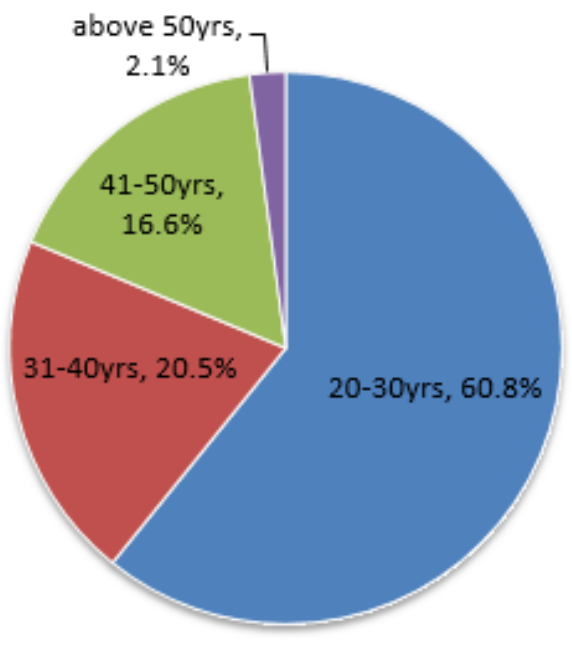

Fig. 1. Age distribution

The age of the participants resulted in $60.8 \%$ for the range of $20-30,20.5 \%$ for the range of $31-40,16.6 \%$ for the range $41-50$, and $2.1 \%$ for participants above 50 .

From the results, the majority of the respondents were in the range of $20-30$ years, which is a true reflection of Botho University when looking at the age of students and staff members herein. Thus, the $20-30$ years age group is the dominant of all the groups.
Fig. 2 below shows the results of the qualification demographic variable.

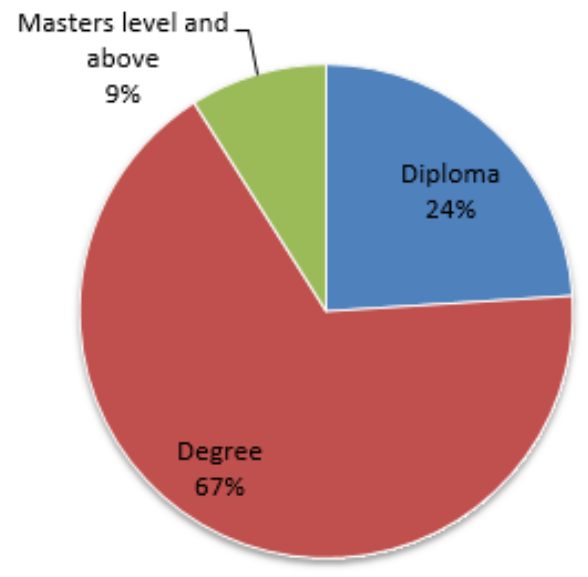

Fig. 2. Qualification distribution

Another demographic variable of qualification resulted in $24 \%$ of the participants having Diplomas, 67\% having Degree qualification and $9 \%$ at masters' level and above.

From the results, it can be concluded that a fair distribution of the questionnaire was done and the majority of the respondents were of the Degree qualification, which is the dominant group in Botho University.

Data summaries were also done for the ICT Opinion questions and analyzed to give solution to the research questions as follows;

\section{Question (a)}

Do Botho University staff and students have any reservations or concerns about ICT adoption and acceptance?

The questions on how the participant's feel on the element of worry about ICT adoption had diverse responses. Therefore, this research does not have statistical clear data that can be used to measure the readiness of Botho University adopting and using ICT. Authors recommend further studies through interviews on computer anxiety or worry.

\section{1) Question (b)}

What are the staff and student's perceptions on the effectiveness of ICT in their school (Botho University)?

In this question, all participants (100\%) strongly agreed that they found computers or ICT useful and effective in the daily delivery of their jobs and or studies.

From the results, it can be concluded that ICT plays a vital role in helping or realizing job delivery at Botho University. Thus having respondents fully agreeing to its role in their daily activities also influences its adoption and acceptance.

2) Sub Question(c)

Do staff and students intend to adopt and use ICT in Botho University? 


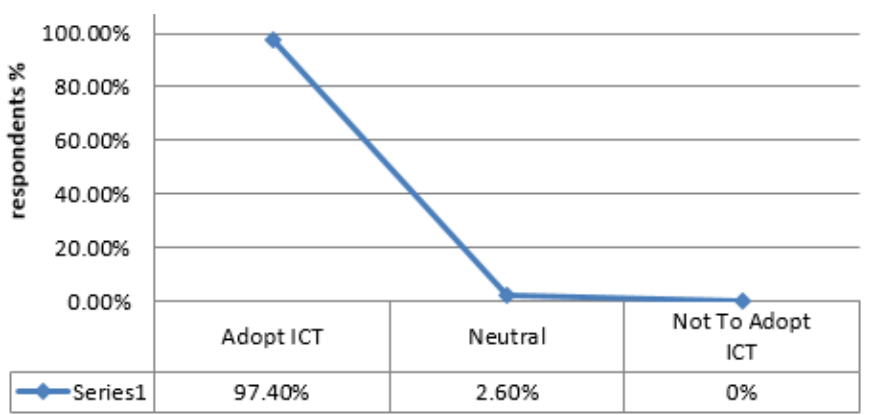

Fig. 3. ICT adoption and acceptance at Botho University

The results for this question produced mixed answers with the scales tipping to the majority who favor ICT adoption. Majority of the participants intend to adopt ICT (97.4\%), just a few are neutral $(2.6 \%)$ and no one does not totally intend to adopt ICT at Botho University. From the results, it can be concluded that majority of the respondents are eager to adopt and embrace the utilization of ICT at Botho University.

\section{CONCLUSION}

From this research, it can be concluded that most people accept the role of ICT in their daily activities and tasks. It has also been concluded that they are still people who are hesitant to adopting and accepting the role of ICT in their tasks $(2.6 \%)$ whilst majority (97.4\%) acknowledges its role. It is not clear as to why some people cannot fully accept or adopt ICT, therefore, authors have concluded that further research needs to be conducted to answer and close this gap.

Finally, with the tested assumption, all participants had a positive feeling towards effectiveness and usefulness of ICT. Therefore, it can be concluded that this positive feeling towards the effectiveness and usefulness of ICT in tertiary schools is a sign of computer technology adoption and acceptance by the participants. It has been determined that Botho University staff and students adopt and accept ICT.

\section{RECOMMENDATION}

- More research needs to be done

More research is needed on this area, with emphasis on the participant's feel and behavior towards ICT adoption, utilization and acceptance. Studies with focus on such would give a clear indication on the ICT adoption and acceptance trend in Botswana Higher Education Sector, and also provide a platform on policy making and implementation.

\section{- Training people on ICT}

ICT literacy is one hurdle impeding the adoption and acceptance of ICT in Institutions of Botswana, thus more training is needed in this area to have majority of people with basic to intermediary skills in the ICT area. This would help people to have relevant ICT skills on their Institutions.

\section{- Early Exposure to ICT}

Many people in Botswana tend to be exposed to ICT technologies at later stages such as during employment or at tertiary levels, which also contributes to delaying ICT adoption and acceptance due to limited and or lack of ICT skills. Thus, early exposure in the form of trainings at work entry level or high schools could help in fuelling ICT adoption at higher education sector [13].

\section{REFERENCES}

[1] Unwin. "Information and communication technology for development. Cambridge": Cambridge University Press, 2009.

[2] Dasgupta, S., Granger, M., \& McGarry, N. User acceptance of ecollaboration technology: An extension of the Technology Acceptance Model. Group Decision and Negotiation, 11, 87-100, 2003

[3] Shavo, "Information technology adoption", 2003

[4] Russell, (2004). People and information technology in the supply chain; social and organizational influences on adoption. International Journal of Physical Distribution and Logistics Management, 34 (2), 102-122.

[5] Long Term Vision 2016: Towards prosperity for all. (1997).From http://vision2016.co.bw/tempimg/media/mediac_103.pdf

[6] Kanos M, (2013)." Challenges faced in Implementing ICT in Higher Learning Institutions. A Botswana perspective". International Journal for Infonomics (IJI), Volume 6, Issues 1/2, 2013

[7] Yusuf, M.O (2005) Information and Communication Technologies and Education: Analyzing the Nigerian National Policy for Information Technology. International Education Journal, 6(3), 316-321.

[8] Bharadwaj, A., S. Bharadwaj and B. Konsynski (1999) "Information Technology Effects on Firm Performance as Measured by Tobin's q", Management Science (45)7, pp. 1008-1024.

[9] Hitt, L. and E. Brynjolfsson (1996) "Productivity, Business Profitability, and Consumer Surplus: Three Different Measures of Information Technology Value", MIS Quarterly (20)2, pp.

[10] Van den Ven, A. H. (1986) "Central Problems in the Management of Innovations", Management Science (32)5, pp. 590-607.

[11] http://laptop.org/en/laptop/hardware/index.shtml (16 March 2012) Cummins, J. (1996) Negotiating Identities: Education and empowerment in a diverse society. Ontario: California Association for Bilingual Education

[12] Cummins, J. (1996) Negotiating Identities: Education and empowerment in a diverse society. Ontario: California Association for Bilingual Education

[13] Maitlamo Botswana's National ICT Policy. (2004). Legislative framework and Change report. Available at http://www.bits.org.bw/downloads/MAITLAMO_NATIONAL_ICT_P OLICY.pdf (Retrieved 19-07-2014)

[14] Botswana National e-government strategy 2011-2016. (2012). Available at http://www.gov.bw/Global/Portal\%20Team/eGovStrategy.pdf (Retrieved from 18 July 2014)

[15] Totolo, A. (2005). Information technology adoption in Botswana secondary schools and implications on leadership and school libraries in the digital age. In S. Lee, P. Warning, D. Singh, E. Howe, L. Farmer and S. Hughes (Eds.), IASL Reports 2005: Information leadership in a culture of change (p. 78). Erie, PA: International Association of School Librarianship.

[16] Bose, K. (2004). Computer Training Programme for primary school teachers in teacher training institutions of the southern region of Botswana. Research in Post Compulsory Education. 